\title{
Дуниты нижней зоны палеопротерозойского Мончетундровского массива: геологические и минералого-геохимические свидетельства процесса океанизации
}

\author{
Чащин В.В., Савченко Е.Э. \\ Геологический институт КНЦ РАН, Anamumbl, chashchin@geoksc.apatity.ru,.evsav@geoksc.apatity.ru
}

\begin{abstract}
Аннотация. Представлены результаты комплексных геологических и минералого-геохимических исследований дунитов, входящих в состав Мончетундровского базитового массива (МБМ) Кольского региона. Дуниты образуют серию дискордантных жильных тел мощностью от 10 до 50 м среди ортопироксенитов и норитов нижней зоны МБМ, реже метагабброидов верхней зоны. Они содержат ксенолит вмещающих ортопироксенитов и активно воздействуют на вмещающие породы. Оливины и хромшпинели дунитов по составу сходны с таковыми альпинотипного массива Падос. В качестве акцессорного минерала в дунитах присутствует аваруит $\left(\mathrm{Ni}_{3} \mathrm{Fe}\right)$, который является типоморфным минералом офиолитовых комплексов. По химическому составу дуниты МБМ близки серпентинитам офиолитов Финляндии и дунитам массива Падос. Они образовались позднее вмещающих пород МБМ, по-видимому, в результате процессов растяжения и спрединга, характеризуя начальный этап формирования океанической коры на Фенноскандинавском щите.
\end{abstract}

Ключевые слова: дуниты, минеральный состав, аваруит, петро-геохимия, океанизация, Мончетундровский массив.

\section{Dunite of the lower zone of the Paleoproterozoic Monchetundra massif: geological and mineralogical-geochemical evidence of the oceanization process}

\author{
Chashchin V.V., Savchenko Ye.E. \\ Geological Institute, Kola Research Center, Russian Academy of Sciences, Apatity, \\ chashchin@geoksc.apatity.ru,evsav@geoksc.apatity.ru
}

\begin{abstract}
Results of complex geological and mineralogical-geochemical studies on dunite, which are part of the Monchetundra basic massif (MBM) in the Kola region, have been presented. The dunite form a series of discordant vein bodies of 10 to $50 \mathrm{~m}$ thickness among orthopyroxenite and norite of the MBM lower zone, less frequently, the upper zone metagabbroid. They contain xenolith of the host orthopyroxenite and actively impact the host rocks. Chemically, olivines and chrome-spinels of the dunite are similar to the ones of the Pados alpinotype massif. As an accessory mineral, awaruite $\left(\mathrm{Ni}_{3} \mathrm{Fe}\right)$, which is a typomorphic mineral of ophiolitic complexes, has been found in the dunite. Chemically, the MBM dunite are similar to ophiolite serpentinite in Finland and the Pados massif dunite. They formed later than the MBM host rocks, presumably, as a result of stretching and spreading processes. This characterises the initial stage of oceanic crust formation on the Fennoscandian Shield.
\end{abstract}

Key words: dunite, mineral composition, avaruite, petro-geochemistry, oceanization, Monchetundra massif.

\section{Введение}

В пределах нижней норит-ортопироксенитовой зоны палеопротерозойского МБМ развиты тела дунитов, на происхождение которых существует две точки зрения. Согласно первой из них дуниты являются членами ритмично расслоенной серии массива, залегая в основании отдельных ритмов (Соколова, 1976; Шарков, 2006; Kunakkuzin et al., 2020). По второй точке зрения (Чащин и др., 2018) дуниты не являются «стратифицированными» образованиями, а образуют серию секущих тел более поздних по отношению к породам МБМ. Учитывая неоднозначность представлений о формировании этих дунитов, были проведены комплексные исследования, включающие изучение вещественного состава дунитов, их минералогических и петро-геохимических особенностей.

\section{Геологическое строение}

Дуниты вскрыты многочисленными поисковыми скважинами и залегают в основном среди ортопироксенитов и норитов нижней зоны МБМ, возраст которых определен в $2496.3 \pm 2.7$ млн. лет 

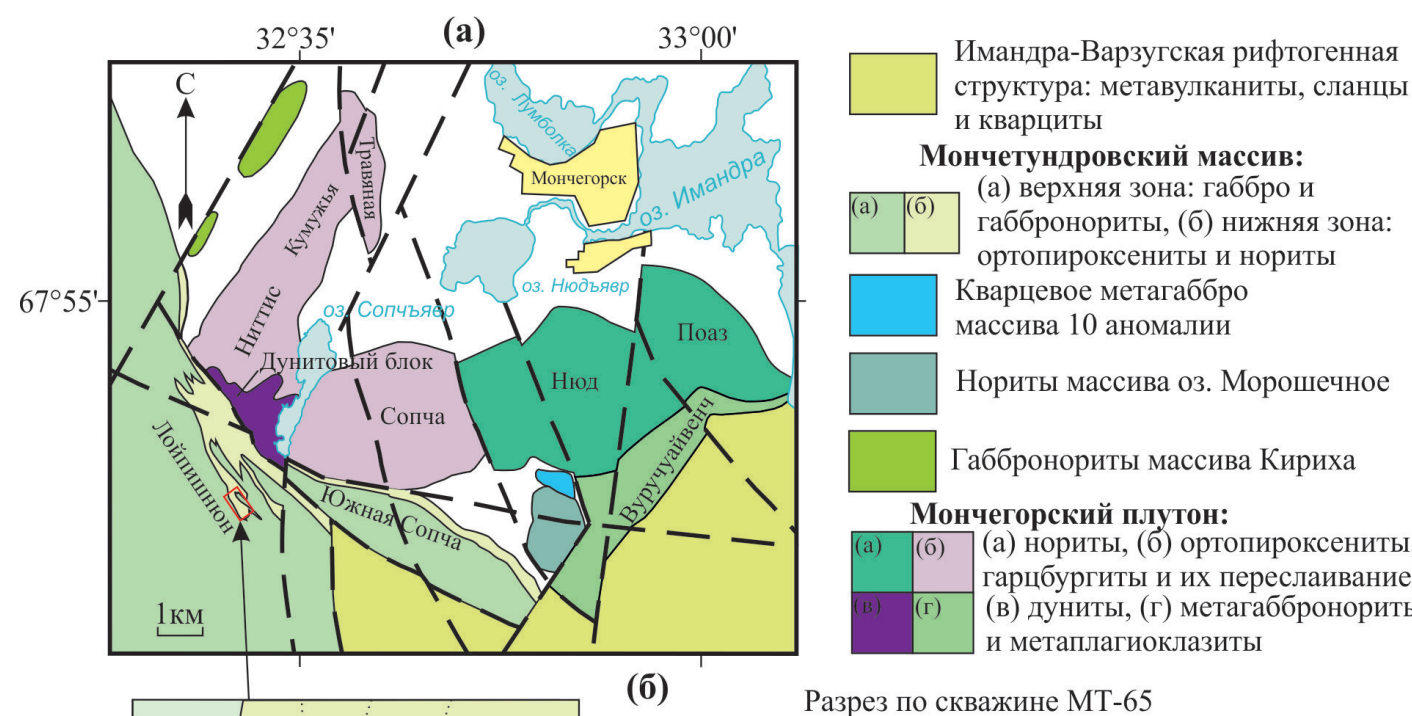
структура: метавулканиты, сланцы и кварциты

Мончетундровский массив:
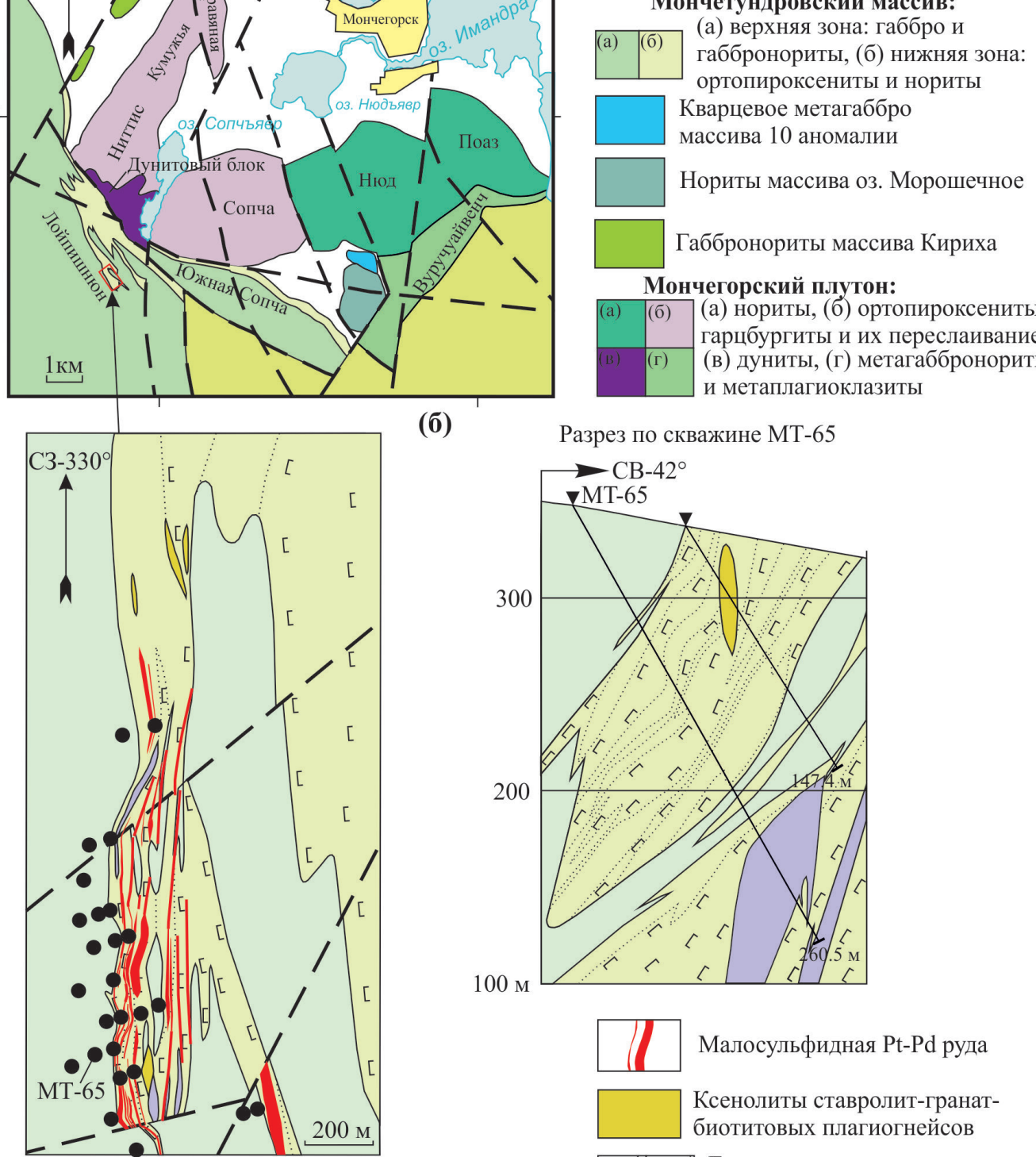

Мончетундровский массив:

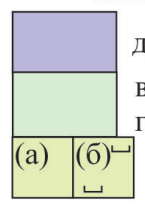
дуниты верхняя зона: метагаббро и метагаббронориты мезо- и лейкократовые

(a) (б) ${ }^{\natural}$ нижняя зона: (а) нориты, (б) ортопироксениты и плагиоортопироксениты

$\prod$ Малосульфидная Pt-Pd руда $\square \begin{aligned} & \text { Ксенолиты ставролит-гранат- } \\ & \text { биотитовых плагиогнейсов }\end{aligned}$ (а)/(б) Геологические границы: (а) достоверные, (б) фациальные

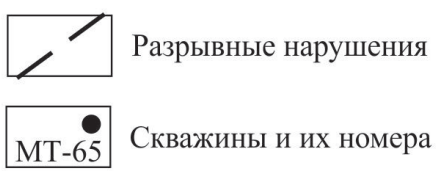

Рис. 1. Схема геологического строения МБМ и Мончегорского плутона (а). Геологическое строение малосульфидного Pt-Pd месторождения Лойпишнюн и разрез по скважине МТ-65 (б).

Fig. 1. Scheme of the MBM and the Monchegorsk pluton geological structure (a). Geological structure of Loipishnyun low-sulfide Pt-Pd deposit and section along borehole MT-65 (b).

и $2500 \pm 2$ млн. лет, соответственно (Чащин и др., 2020). В некоторых случаях дуниты встречаются и среди метагабброидов верхней зоны. Как правило, дуниты не коррелируют между собой по разрезу соседних скважин, образуя сложную сеть дискордантных тел мощностью от первых метров до 50 м. Разрез дунитов изучен по скважине МТ-65, в которой дуниты вскрыты в инт. 197.8-237.1 м, т. е. стволовая мощность дунитов составляет 39.3 м, истинная - около 35 м (рис. 1). В разрезе скважины МТ-65 дуниты представлены чередованием умеренно и интенсивно серпентинизированных разновидностей мощностью от 3 до 15 м. 
На глубине 214.5 м среди серпентинитов встречены, пронизанные тонкими серпентинитовыми прожилками, мелко-среднезернистые плагиоклаз-содержащие амфиболизированные ортопироксениты, являющиеся ксенолитом вмещающих пород. В составе дунитов главные минералы представлены оливином и серпентином, второстепенные - ортопироксеном, хромитом (до 1-2 об. \%), магнетитом (до 2-3 об. \%), хлоритом (до 5 об. \%), акцессорные - аваруитом, хизлевудитом и кобальтпентландитом.

\section{Контактовые соотношения дунитов с вмещающими породами}

Верхний контакт дунитов с ортопироксенитами образует зону мощностью около 5 см. Дуниты в эндоконтакте - это умеренно серпентинизированные мелкозернистые породы (рис. 2 a). По направлению к экзоконтакту они сменяются мелкозернистой амфибол-серпентин-тальковой породой мощностью около 1 мм с неровными границами (рис. 2 a), которая, по-видимому, является переходной между дунитами и метаортопироксенитами. В экзоконтакте развиты мелкозернистые тремолитовые ортоамфиболиты мощностью около 2 см (рис. 2a), которые полностью утратили признаки магматических структур и далее они сменяются мелко-среднезернистыми метаортопироксенитами с реликтами магматических структур.
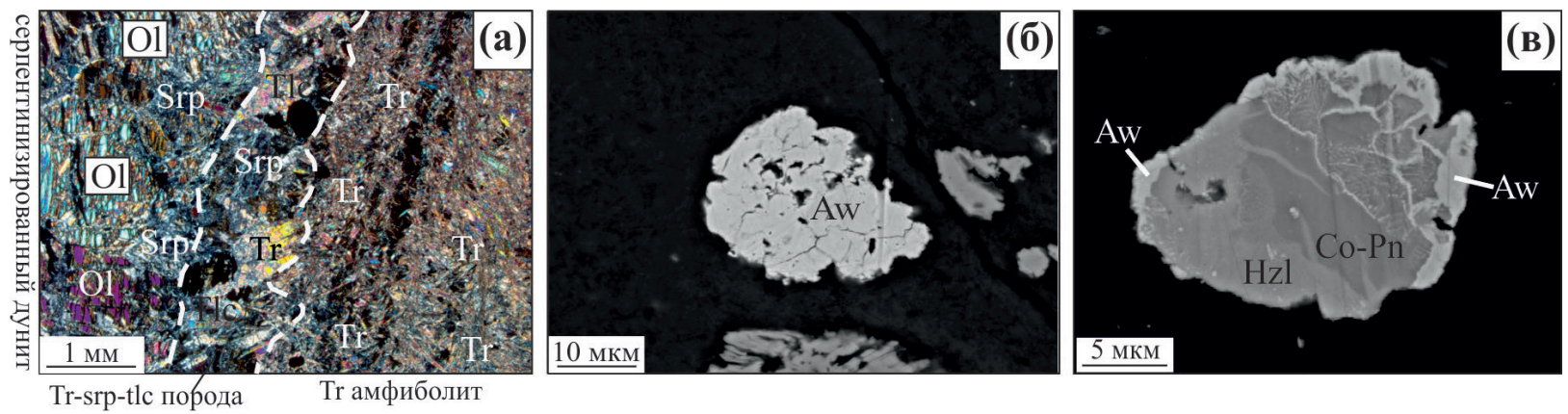

Рис. 2. Контакт серпентинизированного дунита с тремолитовым амфиболитом через зонку тремолит-серпентинтальковой породы мощностью около 1 мм в прозрачном шлифе (а); агрегат аваруита (Aw) (б); кайма аваруита $(\mathrm{Aw})$ по хизлевудиту $(\mathrm{Hzl})$ и кобальт-пентландиту (Co-Pn) с прожилковидными выделениями и тонкими симплектитовыми срастаниями с кобальт-пентландитом (в). Изображения в обратно отраженных электронах.

Fig. 2. Contact of serpentinized dunite with tremolite amphibolite through a zone of tremolite-serpentine-talc rock about $1 \mathrm{~mm}$ thickness in a transparent thin section (a); avaruite aggregate (Aw) (b); avaruite (Aw) rim over heazlewoodite $(\mathrm{Hzl})$ and cobalt-pentlandite $(\mathrm{Co}-\mathrm{Pn})$ with segregations and thin symplectite intergrowths with cobalt-pentlandite (c). Backscattered electron images.

Нижний контакт дунитов с ортопироксенитами выражен не столь отчетливо. В эндоконтакте развиты серпентин-тремолитовые катаклазированные (аподунитовые) породы, которые непосредственно контактируют со среднезернистыми слабо амфиболизированными ортопироксенитами в узкой полосе шириной около 1 мм. В целом, эти наблюдения свидетельствуют о том, что дуниты активно воздействовали на вмещающие ортопироксениты, причем степень этих изменений была более интенсивной в зоне верхнего контакта.

\section{Минералогия}

Оливин в дунитах в основном представлен форстеритом $\left(\mathrm{Fo}_{92.6-90.3}\right)$ и только на контакте с вмещающими ортопироксенитами он сменяется хризолитом $\left(\mathrm{Fo}_{88.3-86.7}\right)$ (рис. 3 a). Содержания $\mathrm{NiO}$ в дунитах находятся в диапазоне 0.50-0.27 мас. \%, при этом, по соотношению магнезиальности оливина (Fo, мол. \%) и содержанию $\mathrm{NiO}$ оливины дунитов МБМ близки таковым альпинотипного массива Падос, отличаясь от серпентинитов офиолитового комплекса Финляндии (рис. 3 a). Хромшпинели относятся, в основном, к группе $\mathrm{Al}$ хромитов с содержанием (мас. \%) $\mathrm{Al}_{2} \mathrm{O}_{3}-13.2-20.9$, $\mathrm{Cr}_{2} \mathrm{O}_{3}-46.6-52.3$ и $\mathrm{MgO}$ - 3.1-9.1. По соотношению $\mathrm{Cr} /(\mathrm{Cr}+\mathrm{Al})-\mathrm{Mg} /\left(\mathrm{Mg}+\mathrm{Fe}^{2+}\right)$ они сходны с таковыми офиолитов Финляндии, но менее хромистые, чем хромшпинели из массива Падос (рис. 3 б). 

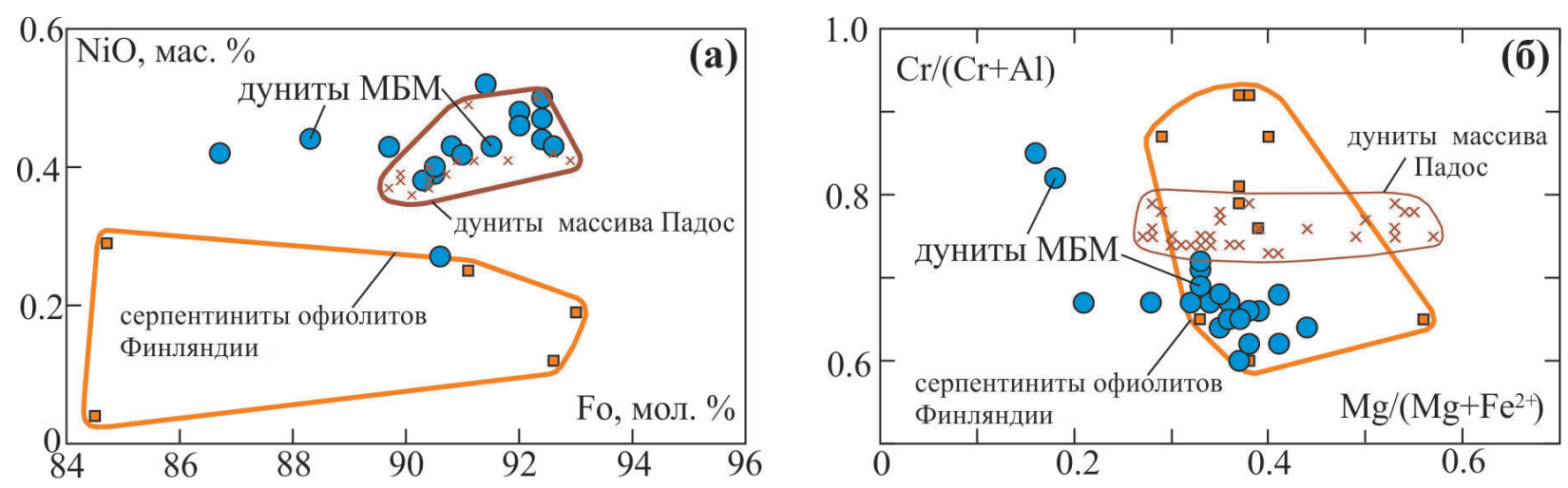

Рис. 3. Диаграмма содержаний $\mathrm{NiO}$, мас. \% - Fo, мол. \% в оливинах из дунитов МБМ в сравнении с составом оливинов из альпинотипного массива Падос, по (Barkov et al., 2017) и серпентинитов офиолитов Финляндии, по (Vuollo, Piirainen, 1989) (a); диаграмма $\mathrm{Cr} /(\mathrm{Cr}+\mathrm{Al})-\mathrm{Mg} /\left(\mathrm{Mg}+\mathrm{Fe}^{2+}\right)$ в хромшпинелидах из дунитов МБМ в сравнении с составами хромшпинелида из массива Падос, по (Barkov et al., 2021) и офиолитов Финляндии, по (Vuollo, Piirainen, 1989) (б).

Fig. 3. NiO wt. \% vs.Fo, mol. \% plot in olivines from MBM dunite in comparison with the ones from the Pados alpine massif, after (Barkov et al., 2017) and serpentinite of ophiolites in Finland, after (Vuollo and Piirainen, 1989) (a); Cr/ $(\mathrm{Cr}+\mathrm{Al}) \mathrm{vs} . \mathrm{Mg} /\left(\mathrm{Mg}+\mathrm{Fe}^{2+}\right)$ plot in Cr-spinels from MBM dunite in comparison with the ones from the Pados massif, after (Barkov et al., 2021) and ophiolite of Finland, after (Vuollo, Piirainen, 1989) (b).

Характерным акцессорным минералом серпентинизированных дунитов является аваруит $\left(\mathrm{Ni}_{3} \mathrm{Fe}\right)$. Он образует гомогенные агрегаты мелких зерен суммарным размером $20 \times 30$ мкм (рис. 2 б), тонкие срастания с кобальтпентландитом и хизлевудитом и узкие каймы вокруг них (рис. 2в). Аваруит является типоморфным минералом офиолитовых комплексов и концентрически-зональных интрузий. Поскольку МБМ не относятся к последним из них, наличие аваруита в его дунитах служит одним из показателем их принадлежности к офиолитам.

\section{Химический состав дунитов}

Дуниты характеризуются высокими содержаниями магния (MgO 39.2-41.0 мас. \%) и никеля ( $\mathrm{Ni} 1600-3000$ г/т), повышенными - хрома $\left(\mathrm{Cr}_{2} \mathrm{O}_{3}\right.$ 0.2-0.7 мас. \%), низкими - кремнезема $\left(\mathrm{SiO}_{2}\right.$ 35.0-36.5 мас. \%), глинозема $\left(\mathrm{Al}_{2} \mathrm{O}_{3}\right.$ 0.7-1.3 мас. \%) и кальция (СаO до 0.4 мас. \%), которые
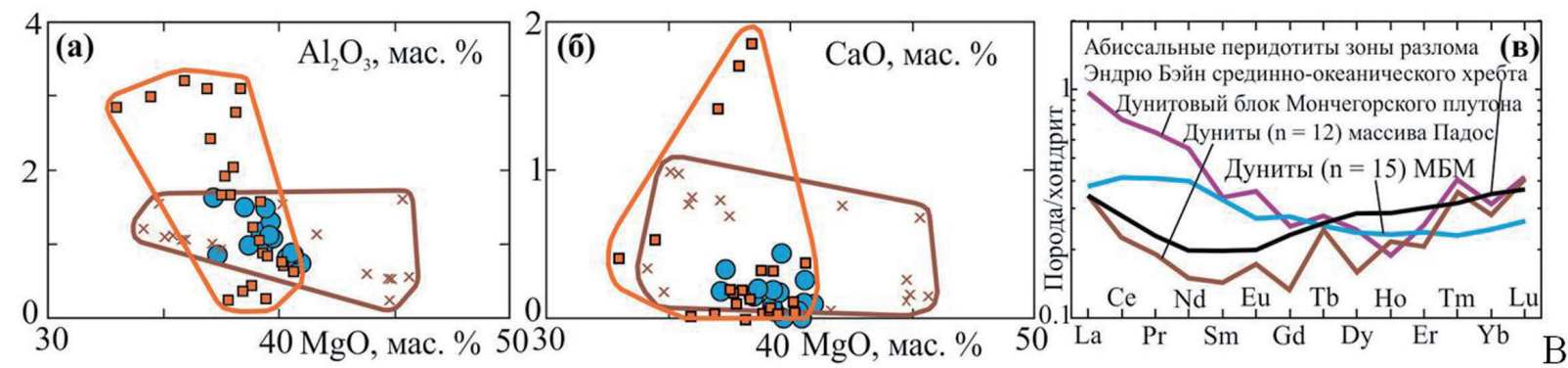

Рис. 4. Диаграммы $\mathrm{MgO}-\mathrm{Al}_{2} \mathrm{O}_{3}$ (а) и $\mathrm{MgO}-\mathrm{CaO}$ (б) для дунитов МБМ в сопоставлении с аналогичными породами альпинотипного массива Падос, по (Barkov et al., 2021) и офиолитами Финляндии, по (Vuollo, Piiranen, 1989; Peltonen et al., 1998). Условные обозначения см. рис. 3. Средние спектры РЗЭ, нормированных на хондрит С1, в дунитах МБМ, Мончегорского плутона, по (Криволуцкая и др., 2010), массива Падос, по (Barkov et al., 2021) и абиссальных перидотитов срединно-океанических хребтов, по (Niu, 2004) (в).

Fig. 4. $\mathrm{MgO}$ vs. $\mathrm{Al}_{2} \mathrm{O}_{3}$ (a) and $\mathrm{MgO}$ vs. $\mathrm{CaO}$ (b) plots for $\mathrm{MBM}$ dunite in comparison with ones of the Pados alpine massif, after (Barkov et al., 2021) and ophiolite of Finland, after (Vuollo, Piiranen, 1989; Peltonen et al., 1998). Legend see fig. 3. Average REE spectra, normalized to C1, in MBM dunite, Monchepluton, after (Krivolutskaya et al., 2010), Pados massif, after (Barkov et al., 2021) and mid-oceanic ridges abyssal peridotite, after (Niu, 2004) (c). 
свойственны типовым породам такого состава. По распределению $\mathrm{Al}_{2} \mathrm{O}_{3}$ и СаО относительно содержаний $\mathrm{MgO}$ дуниты МБМ близки как аналогичным породам массива Падос, так и офиолитам Финляндии (рис. 4 а-б).

Содержания РЗЭ в дунитах характеризуются низкими значениями, на уровне 0.2-0.7 относительно хондрита с повышенными содержаниями ЛРЗЭ относительно ТРЗЭ, что выражается в отрицательном наклоне графика на диаграмме в диапазоне элементов Ce-Gd (рис. 4 в). По характеру распределения РЗЭ дуниты МБМ не имеют аналогов среди таковых пород из типовых геодинамических обстановок, отличаясь от дунитов Мончегорского плутона, массива Падос и абиссальных перидотитов срединно-океанических хребтов (рис. 4 в).

\section{Заключение}

В результате проведенных исследований получены достаточно убедительные свидетельства того, что дуниты МБМ не являются членами его нижней расслоенной зоны, а скорее всего, принадлежат к более молодым образованиям, вероятно, океанической коры. Это обусловлено: наличием в дунитах ксенолита вышележащих ортопироксенитов, воздействием дунитов на вмещающие породы; наличием минералого-петрохимических критериев сходства состава минералов и дунитов с соответствующими минералами и породами альпинотипных интрузий и офиолитов и, наконец, присутствие в составе дунитов типоморфного для офиолитов минерала аваруита. Такой набор признаков в значительной степени свидетельствуют о близости дунитов МБМ к образованиям океанической коры. Некоторое различие наблюдается только при сравнении спектров РЗЭ, однако, как показали исследования (Niu, 2004) абиссальные ультрабазиты различных сегментов одних и тех же срединно-океанических хребтов обладают различающимися спектрами РЗЭ.

По всей видимости, образование дунитов МБМ происходило во время 2.1-2.0 млрд. лет и сопряжено с начальным этапом процесса океанизации континентальной коры Кольского кратона. Согласно (Abbate et al., 1994) существует три возможных механизма океанизации: (1) зоны трансформных разломов, (2) очень медленный спрединг и (3) коровая деламинация. Вероятно, в случае с дунитами МБМ можно предположить, что их образование связано с медленным спредингом, происходившим при разрыве континентальной коры.

Работа выполнена на материалах и с разрешения $3 \mathrm{AO}$ «Терская горная компания» в рамках темы НИР 0226-2019-0053 при частичной финансовой поддержке РФФИ из средств гранта 18-05-70082.

\section{Литература}

1. Криволуцкая Н.А., Смолькин В.Ф., Свирская Н.М., Мамонтов В.П., Фаныгин А.С., Беляцкий Б.В., Рощина И.А. Геохимические особенности массивов друзитового комплекса центральной части Беломорского подвижного пояса: I. Распределение главных и редких элементов в породах // Геохимия. 2010. № 3. C. 16-44.

2. Соколова В.Н. Новые данные о геологическом строении интрузивного комплекса Монче-Чуна-Волчьих тундр (Кольский п-ов) // Советская геология. 1976. № 6. С. 100-111.

3. Чащин В.В., Петров С.В., Дрогобужская С.В. Малосульфидное платино-палладиевое месторождение Лойпишнюн Мончетундровского базитового массива (Кольский полуостров, Россия) // Геология рудных месторождений. 2018. Т. 60. № 5. С. 472-503. DOI: 10.1134/S0016777018050027.

4. Чащин В.В., Баянова Т.Б, Савченко Е.Э., Киселева Д.В., Серов П.А. Петрогенезис и возраст пород нижней платиноносной зоны Мончетундровского базитового массива, Кольский полуостров // Петрология. 2020. Т. 28. № 2. С. 150-183. DOI: 10.31857/S0869590320020028.

5. Шарков Е.В. Формирование расслоенных интрузивов и связанного с ними оруденения. М. Изд-во: Научный мир. 2006. 368 с.

6. Abbate E., Bortolotti V., Passerini P., Principi G., Treves B. Oceanisation processes and sedimentary evolution of the Nortnern Apennine ophiolite suite: a discussion // Memorie Societa Geologica Italiana. 1994. 48. P. 117-136.

7. Barkov AY., Nikiforov AA., Barkova LP., Korolyuk VN., Martin R.F. Zones of PGE-chromite mineralization in relation to crystallization of the Pados-Tundra ultramafic complex, Serpentinite Belt, Kola Peninsula, Russia // Minerals. 2021. https://doi.org/dx.doi.org/10.339/min11010068. 
8. Kunakkuzin E., Borisenko E., Nerovich L., Serov P., Bayanova T., Elizarov D. The origin and evolution of ore-bearing rocks in the Loypishnun deposit (Monchetundra Massif, NE Fennoscandian Shiels): isotope Nd-Sr and REE geochemical data // Minerals. 2020. DOI: 10.3390/min10030286.

9. Peltonen P., Kontinen A., Huhma H. Petrogenesis of the mantle sequence of the Jormua ophiolite (Finland): melt migration in the upper mantle during paleoproterozoic continental break-up // Journal of Petrology 1998. 39. P. 297-329.

10. Vuollo J., Piirainen T. Mineralogical evidence for an ophiolite from the Outokumpu serpentinites in North Karelia, Finland // Bulletin of the Geological Society of Finland. 1989. 61. P. 95-112. 